\title{
Don't toss the excess: Using the redundant truncal valve cusp may improve repair for truncus arteriosus
}

\author{
Travis J. Wilder, MD
}

From the Department of Cardiothoracic Surgery, University of Utah, Salt Lake City, Utah.

Disclosures: Author has nothing to disclose with regard to commercial support.

Received for publication Oct 11, 2017; accepted for publication Oct 13, 2017; available ahead of print Dec 15, 2017.

Address for reprints: Travis J. Wilder, MD, Division of Cardiothoracic Surgery, University of Utah, 30 North 1900 East, \#3C127 SOM, Salt Lake City, UT 84132 (E-mail: travis.wilder@hsc.utah.edu).

J Thorac Cardiovasc Surg 2018;155:1190-1

0022-5223/\$36.00

Copyright (c) 2017 by The American Association for Thoracic Surgery

https://doi.org/10.1016/j.jtcvs.2017.10.042

Since the first successful intracardiac repair for truncus arteriosus (TA) described by Behrendt and colleagues, ${ }^{1}$ surgical management for patients with TA has considerably improved. ${ }^{2}$ Reported survival is as high as $95 \%$ at 15 years in some series and was similar irrespective of the timing of surgery for all children aged less than 1 year. $^{3}$ Despite the improved survival for patients with TA as a whole, those with associated truncal valve insufficiency (TVI) have significantly worse outcomes. ${ }^{2,4}$ Pre-repair TVI has consistently been shown to be a strong risk factor for death after TA repair with prior research demonstrating that a concomitant truncal valve procedure during primary repair is associated with a 3 -fold increase in mortality compared with patients who undergo repair without truncal valve intervention. ${ }^{2}$

In the current issue of the Journal, Wei and colleagues 5 present a case report describing a novel surgical technique to repair a quadricuspid truncal valve in an infant with type I TA and severe TVI. Specifically, a tricuspidization technique was used. However, rather than completely resecting the redundant leaflet, which has been previously described (Central Image), the accessory cusp, sinus, and annular complex were excised and rotated as a pedicle flap to reconstruct the right ventricular outflow tract floor (Figure 1). ${ }^{6}$

The increased risk associated with TVI is multifactorial, but is at least in part related to the gap in knowledge with respect to the selecting the best surgical strategy. Although the tenants for TA repair are generally agreed on and include pulmonary artery separation, ventricular septal defect closure, and reconstruction of the right ventricular outflow tract, strategies for surgical correction of the truncal valve have not been standardized. ${ }^{2,4}$ In patients with TA, truncal valve pathology is variable and commonly includes valves with 4 leaflets (quadricuspid), thickened or irregular leaflets, abnormal number and location of commissures, and variation in the size of the truncal valve annulus. As such, it is no surprise that a variety of repair techniques have been described, including suture closure of adjacent leaflets, resection or exclusion of rudimentary leaflets, annular plasties, leaflet extension with autologous pericardium, and commissuroplasties. $^{2}$

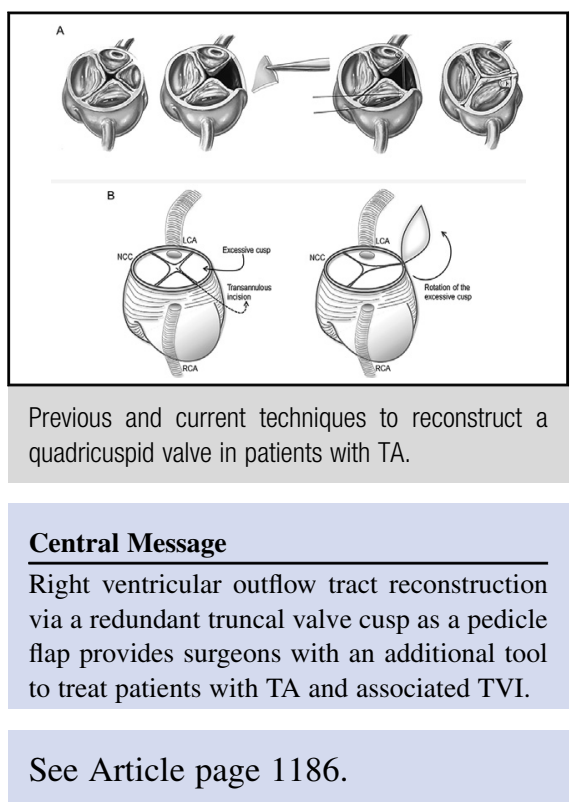

Untreated TVI at the time of initial TA repair results in unfavorable hemodynamics that not only increase the risk of mortality but also increase the risk of truncal valve reintervention. ${ }^{3}$ Therefore, neutralizing TVI is an important step during any TA repair. For quadricuspid valves, constructing an anatomic or functional trileaflet structure as provided durable results for patients with TVI. ${ }^{2,6}$ Of note, the current strategy reduces the annular size and restores the neoaortic valve to a more native anatomic configuration. Another important distinguishing feature of the described operation is that by incorporating native tissue to partially reconstruct the right ventricular outflow tract, the growth potential of the outflow tract may be improved, thus potentially decreasing the need for future interventions.

The allure of any novel surgical technique must be balanced against a paucity of evidence. The authors should be commended for their ingenuity in treating a complex surgical problem and their excellent outcomes. However, it should be mentioned that more time and experience are necessary to test the durability of this strategy. Nevertheless, this innovative technique provides an additional recourse for surgeons next time they are faced with correcting TVI in a patient with TA.

\section{References}

1. Behrendt DM, Kirsh MM, Stern A, Sigmann J, Perry B, Sloan H. The surgical therapy for pulmonary artery-right ventricular discontinuity. Ann Thorac Surg. 1974; $18: 122-37$. 

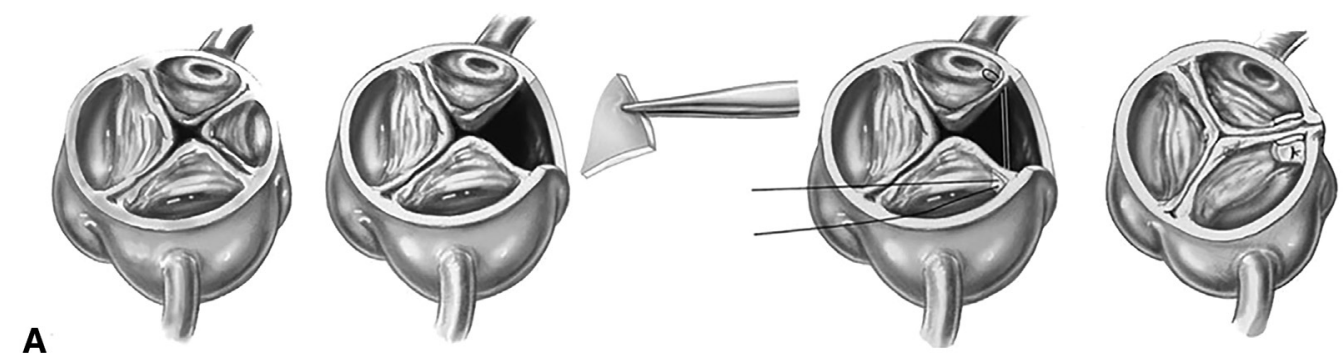

B
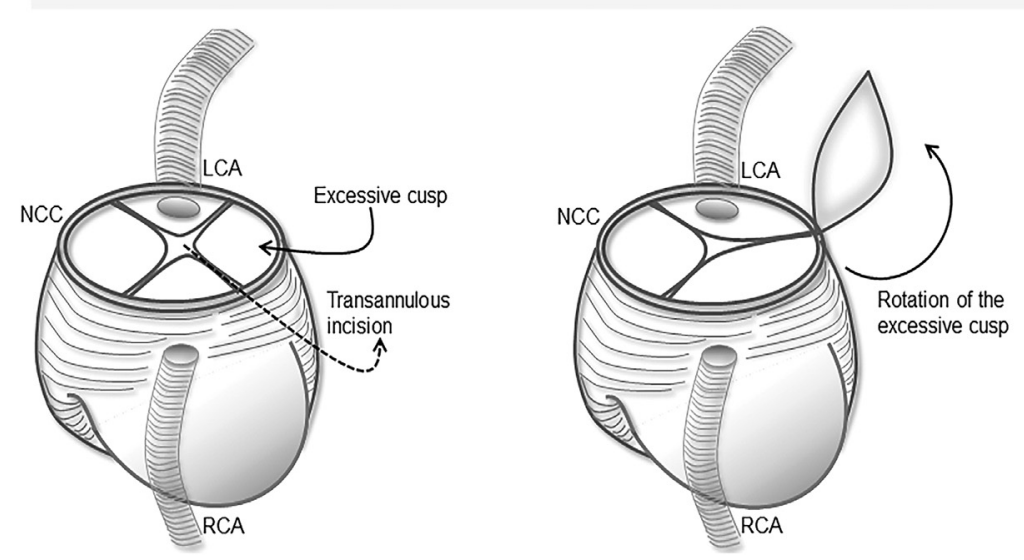

FIGURE 1. A, Resection and removal of rudimentary leaflet with subsequent tricuspidization. Reproduced wtih permission from Imamura et al. ${ }^{6} \mathrm{~B}$, The described technique by Wei and colleagues for leaflet approximation and reconstruction of the right ventricular outflow tract using the accessory cusp. ${ }^{5} L C A$, Left coronary artery; $N C C$, non-coronary cusp; $R C A$, right coronary artery.

2. Myers PO, Bautista-Hernandez V, del Nido PJ, Marx GR, Mayer JE, Pigula FA, et al. Surgical repair of truncal valve regurgitation. Eur J Cardiothorac Surg. 2013;44:813-20.

3. Rajasinghe HA, McElhinney DB, Reddy VM, Mora BN, Hanley FL. Long-term follow-up of truncus arteriosus repaired in infancy: a twenty-year experience. J Thorac Cardiovasc Surg. 1997;113:869-79.

4. Mavroudis C, Jonas RA, Bove EL. Personal glimpses into the evolution of truncus arteriosus repair. World J Pediatr Congenit Heart Surg. 2015;6:226-38.
5. Wei LY, Chen YS, Chiu IS, Huang SC. Repair of a quadricuspid truncal valve by tricuspidization and reconstruction of right ventricular outflow tract with the excised truncal cusp. J Thorac Cardiovasc Surg. 2018;155: 1186-9.

6. Imamura M, Drummond-Webb JJ, Sarris GE, Mee RB. Improving early and intermediate results of truncus arteriosus repair: a new technique of truncal valve repair. Ann Thorac Surg. 1999;67:1142-6. 